\title{
The role of growth hormone and glucocorticoid in glucose handling in vivo
}

\author{
T Johansen ${ }^{1}$, M Deckert ${ }^{2}$, T Mandrup-Poulsen ${ }^{2}$ and K Malmlöf ${ }^{1}$ \\ ${ }^{1}$ Novo Nordisk A/S, Health Care Discovery, Growth Hormone Pharmacology, Gentofte, Denmark \\ ${ }^{2}$ Steno Diabetes Center, Gentofte, Denmark \\ (Requests for offprints should be addressed to T Johansen, Novo Nordisk A/S, Novo Nordisk Park, F9.S.26, DK-2760 Måløv, Denmark)
}

\begin{abstract}
Growth hormone (GH) can oppose the catabolic effects of glucocorticoids. However, both hormones have adverse effects on carbohydrate metabolism. Here we examined the interactive effects of $\mathrm{GH}$ and the glucocorticoid methylprednisolone (MP) on glucose tolerance, insulin resistance and $\left[{ }^{3} \mathrm{H}\right] 2,6$-deoxyglucose uptake of peripheral tissues in rats.

Female Wistar rats received either saline, GH $(2.7 \mathrm{mg} /$ $\mathrm{kg})$, MP $(5.0 \mathrm{mg} / \mathrm{kg})$ or $\mathrm{GH}+\mathrm{MP}$. After 7 days treatment, animals were subjected to an i.v. glucose tolerance test. In a second experiment, animals treated as above were anesthetized and injected with human insulin $(0.5 \mathrm{U} / \mathrm{kg})$, $\left[{ }^{3} \mathrm{H}\right] 2,6$-deoxyglucose $(500 \mu \mathrm{Ci} / \mathrm{kg})$, and $\left[{ }^{14} \mathrm{C}\right]$ mannitol $(25 \mu \mathrm{Ci} / \mathrm{kg})$, to estimate insulin resistance and $\left[{ }^{3} \mathrm{H}\right] 2,6-$ deoxyglucose uptake in fat and muscle.

Weight gain in controls was $7 \cdot 6 \pm 1.7 \mathrm{~g}$, while $\mathrm{GH}$ treatment increased the mean body weight by $18 \cdot 7 \pm 2 \cdot 2 \mathrm{~g}(P<0 \cdot 0002)$ and MP inhibited weight gain down to $0 \cdot 0 \pm 1 \cdot 0 \mathrm{~g}(P<0 \cdot 004)$. This drop in weight gain was reversed back to normal when $\mathrm{GH}$ was given in

combination with MP. After a glucose tolerance test no significant differences in glucose area under the curve were detected when comparing individual groups with the control group, but samples taken just before this test revealed that basal insulin was significantly elevated in the group treated with $\mathrm{GH}(174 \pm 27 \mathrm{pM}, P<0 \cdot 008)$, or GH+MP (209 $\pm 21 \mathrm{pM}, P<0 \cdot 004)$, when compared with controls $(107 \pm 17 \mathrm{pM})$. MP alone had no effect $(122 \pm 19, P<0 \cdot 3)$. After an i.v. bolus of insulin the group receiving $\mathrm{GH}+\mathrm{MP}$ had a significantly $(P<0 \cdot 007)$ higher level of circulating glucose compared with controls $(6.5 \pm 0.3 \mathrm{mM}$ vs $4.4 \pm 0.7 \mathrm{mM})$. Despite this, there were no differences in peripheral glucose uptake between the two groups.

In conclusion this study shows that a combined administration of GH and MP decreases the potency by which insulin decreases circulating glucose levels, but that peripheral tissues are not primarily involved in this insulin resistance.

Journal of Endocrinology (1999) 162, 87-93
\end{abstract}

\section{Introduction}

Growth hormone $(\mathrm{GH})$ and glucocorticoids are potent regulators of metabolism (Davidson 1987, Dallman et al. 1993, Yarasheski 1994, Haymond \& Mauras 1996). Glucocorticoids induce proteolysis and inhibit protein synthesis, resulting in decreased nitrogen balance and weight loss (Ortoft et al. 1992, Strack et al. 1995, Weinstein et al. 1995). Thus, extensive therapy with high doses of glucocorticoids induces a risk for serious protein wasting. Furthermore, glucocorticoids cause insulin resistance and impair glucose utilisation resulting in hyperglycemia and hyperinsulinemia (Marfaing et al. 1991).

Recent studies show that the protein anabolic action of $\mathrm{GH}$ has a potential role in the treatment of catabolism (Haymond \& Mauras 1996). Accordingly, GH has been shown to increase net balance of amino acids in the human forearm (Fryberg et al. 1991, 1992) and in the hind limbs of pigs (Malmlöf et al. 1994a), improve whole body leucine balance in humans (Horber et al. 1991) and increase body weight (Ortoft et al. 1992). However, a major drawback of $\mathrm{GH}$ administration is the diabetogenic actions of the hormone (Davidson 1987), thus complicating its use in conditions with glucocorticoid excess. The combined effect of GH and glucocorticoids regarding glucose and insulin levels appear more dramatic than when using the hormones alone (Haymond \& Mauras 1996) and require further studies.

This study was performed to investigate the ability of $\mathrm{GH}$ to counteract the growth retarding effect of the glucocorticoid methylprednisolone (MP), and to elucidate further the effects of GH and MP on glucose handling. MP was employed to induce a controlled state of catabolism (Horber et al. 1991, Ortoft et al. 1992). GH and MP were administered singly or in combination. The actions of the hormones on carbohydrate metabolism were 
investigated with an intravenous glucose tolerance test, insulin challenge and with a glucose tracer technique, measuring intracellular glucose accumulation in muscle and fat.

\section{Materials and Methods}

\section{Animals and treatment}

Study 1 Twenty-five three-month-old female Wistar rats, initially weighing an average of $207 \mathrm{~g}$, were kept at constant temperature and humidity and under a $12 \mathrm{~h} / 12 \mathrm{~h}$ light/darkness cycle. The animals were randomly assigned to four treatment groups. One received saline alone (control, $n=5$ ), another received recombinant rat $\mathrm{GH}$ (Geneworks, Rundle Mall, Adelaide, Australia) and saline (GH, $n=6$ ), a third received MP (Solu Medrol, Pharmacia \& Upjohn, Rijksweg 12, Puurs, Belgium) and saline (MP, $n=6)$ and a fourth was treated with GH and MP simultaneously $(\mathrm{GH}+\mathrm{MP}, n=8)$. GH was given in two equal doses morning and afternoon in a total daily dose of $2.7 \mathrm{mg} / \mathrm{kg}$, and MP was given once each morning in a daily dose of $5 \cdot 0 \mathrm{mg} / \mathrm{kg}$. All solutions were given subcutanously in volumes of $1.0 \mathrm{ml} / \mathrm{kg}$. Treatment continued for 7 days and animals were weighed in the morning every day.

Surgical procedures After one week in the animal facility animals were fitted with permanent indwelling catheters in the left carotid artery and the right jugular vein (Tygon Microbore Tubing, Norton Performance Plastic, Corby, Northamptonshire, UK). A mixture of halothan, nitrogendioxide and oxygen was used for anesthesia. The catheters were led subcutanously to the back of the neck. They were filled with polyvinylpyrrolidon (PVP K30, Fluka Chemicals, Buchs, Switzerland) $(300 \mathrm{mg} / \mathrm{ml})$ and heparin $(500 \mathrm{U} / \mathrm{ml})$ in $0.9 \%$ saline, or glucose $(500 \mathrm{mg} / \mathrm{ml})$ and heparin $(500 \mathrm{U} / \mathrm{ml})$ in $0.9 \%$ saline and closed with fishing line. During the procedure the animals received antibiotic (Borgal Mite Vet., Hoechst Veterinär GmbH, Unterschleissheim, Germany) and analgesic (Finadyne Vet., Scanvet, Fredensborg, Denmark).

Experimental procedures During the week following surgery animals were accustomed to the test facilities after which treatments were initiated. On the morning of the last treatment day food was removed, and solutions in the catheters were replaced with heparin containing $20 \mathrm{U} / \mathrm{ml}$ saline $(0 \cdot 9 \%)$. Three to four hours later blood was sampled for glucose, rat insulin, insulin-like growth factor-I (IGF-I) and rat GH. The intravenous glucose tolerance test was then performed. The animals were given $1 \cdot 0 \mathrm{~g} / \mathrm{kg}$ glucose in $0.9 \%$ saline solution as a bolus in volumes of $2 \cdot 0 \mathrm{ml} / \mathrm{kg}$ through the jugular vein catheter. Blood was sampled for plasma analysis of glucose and insulin at 0,5 , 15, 30, 60 and $120 \mathrm{~min}$. All samples were kept on ice until centrifugation (3 min, 10000 r.p.m.), and were then refrigerated $\left(5^{\circ} \mathrm{C}, \mathrm{GH}\right.$ samples $)$ or frozen $\left(-20{ }^{\circ} \mathrm{C}\right.$, all others). Immediately after this the animals were given an intravenous overdose of pentobarbital.

Study 2 Thirty-five female Wistar rats, on average weighing $211 \mathrm{~g}$ were treated as in study 1. In this experiment there were 6 animals in the control group, 11 in the GH group, 7 in the MP group, and 11 in the group receiving both hormones $(\mathrm{GH}+\mathrm{MP})$. The animals were kept in metabolism cages during treatment.

Surgical procedures After 7 days of treatment animals were fitted with indwelling catheters in the left carotid artery (polyethylene) during pentobarbital anesthesia $(60 \mathrm{mg} / \mathrm{kg})$. Catheters were filled with heparin in $0.9 \%$ saline $(20 \mathrm{U} / \mathrm{ml})$ to prevent occlusion.

Experimental procedures Food was removed on the morning of the last treatment day. During anesthesia blood samples were withdrawn for analysis of glucose, prior to insulin challenge and glucose uptake measurement. This consisted of injection of a $0.2 \%$ albumin solution (Bovine Serum Albumin, Sigma, St Louis, MO, USA) containing human insulin (Actrapid, Novo Nordisk, Gentofte, Denmark), 0.5 U/kg, $\left[{ }^{3} \mathrm{H}\right] 2$,6-deoxyglucose, $500 \mu \mathrm{Ci} / \mathrm{kg}$, and $\left[\mathrm{U}_{-}{ }^{14} \mathrm{C}\right]$ mannitol, $25 \mu \mathrm{Ci} / \mathrm{kg}$ (Amersham International, Amersham, Bucks, UK), through the catheter over $30 \mathrm{~s}$. The catheter was rinsed by filling it with blood three times before closing it. Twentyfive minutes after insulin injection the blood was sampled for analysis of glucose, IGF-I and isotope content. The rats were then decapitated and the entire soleus muscle, the long digital extensor muscle (soleus and EDL respectively), and $50-100 \mathrm{mg}$ inguinal subcutaneous and intraabdominal fat were removed. Tissue samples were frozen immediately on solid nitrogen and stored at $-80^{\circ} \mathrm{C}$. The muscles were chosen because of their fibre type composition. The soleus muscle consists of $89 \%$ slow twitch oxidative fibres, and EDL muscle consists of 79\% fast twitch glycolytic fibres (Armstrong \& Phelps 1984).

\section{Measurement of $\left.\beta^{3} H\right]$ deoxyglucose uptake}

The method used for determination of $\left[{ }^{3} \mathrm{H}\right]$ deoxyglucose uptake was modified from Hom et al. (1984). In the present study the extracellular tracer molecule $\left[\mathrm{U}_{-}{ }^{14} \mathrm{C}\right]$ sucrose was replaced by $\left[\mathrm{U}_{-}{ }^{14} \mathrm{C}\right] \mathrm{mannitol}$. Because mannitol is a monosaccharide like glucose it would therefore in theory be a better extracellular tracer than the disaccharide sucrose, as it is likely to share the dispersion kinetics of glucose. Frozen tissue samples were weighed directly into $20 \mathrm{ml}$ glass scintillation vials, $1.0 \mathrm{ml}$ BTS-450 toluene solubiliser (Beckmann, Brea, CA, USA) was added, and the vials were left at $55{ }^{\circ} \mathrm{C}$ overnight. Next 
Table 1 Data from study 1: basal plasma glucose and insulin, peak values after $5 \mathrm{~min}$, and area under the curve (AUC) after 120 min, during an i.v. glucose tolerance test $(1.0 \mathrm{~g} / \mathrm{kg})$ in rats after 7 days of treatment with saline (Control), rat growth hormone $2 \cdot 7 \mathrm{mg} / \mathrm{kg}(\mathrm{GH})$, methylprednisolone $5.0 \mathrm{mg} / \mathrm{kg}(\mathrm{MP})$ or $\mathrm{GH}$ and $\mathrm{MP}$ in the same doses as in the groups treated with only one hormone $(\mathrm{GH}+\mathrm{MP})$. Values are presented as means \pm S.E.M.

\begin{tabular}{|c|c|c|c|c|}
\hline & Control & GH & MP & $\mathrm{GH}+\mathrm{MP}$ \\
\hline \multicolumn{5}{|l|}{ Glucose } \\
\hline Basal (mM) & $8 \cdot 3 \pm 0 \cdot 3$ & $8 \cdot 0 \pm 0 \cdot 3$ & $8 \cdot 9 \pm 1 \cdot 1$ & $9 \cdot 5 \pm 0 \cdot 5$ \\
\hline Peak (mM) & $22 \cdot 7 \pm 0 \cdot 9$ & $27 \cdot 5 \pm 2 \cdot 4$ & $25 \cdot 3 \pm 1 \cdot 0$ & $26 \cdot 1 \pm 1 \cdot 5$ \\
\hline $\mathrm{AUC}(\mathrm{mM} / \mathrm{min})$ & $1064 \pm 62$ & $1149 \pm 76$ & $1337 \pm 53$ & $1276 \pm 67$ \\
\hline \multicolumn{5}{|l|}{ Insulin } \\
\hline Basal (pM) & $107 \pm 17$ & $174 \pm 27^{*}$ & $122 \pm 19$ & $209 \pm 21^{* *}$ \\
\hline Peak (pM) & $1182 \pm 263$ & $1406 \pm 294$ & $554 \pm 73$ & $916 \pm 100$ \\
\hline $\mathrm{A} \cup \mathrm{C}(\mathrm{pM} / \mathrm{min})$ & $19933 \pm 3105$ & $32450 \pm 4574$ & $25160 \pm 4889$ & $39260 \pm 3253^{* * *}$ \\
\hline
\end{tabular}

${ }^{*} P<0 \cdot 008,{ }^{* *} P<0 \cdot 004,{ }^{* * *} P<0 \cdot 003$ compared with controls.

day $10 \mathrm{ml}$ scintillation liquid (Hi Safe, Beckmann) and $80 \mu \mathrm{l}$ iced acetic acid were added, and samples were counted using external standards, with a double isotope counter program in a liquid scintillation counter (Beckmann LS6000). Each tissue type was counted separately and the value of the blank samples was subtracted. Calculations of intracellular $\left[{ }^{3} \mathrm{H}\right]$ deoxyglucose uptake was carried out as described by Hom et al. (1984).

\section{Blood analyses}

Blood was drawn into tubes containing 4-8 $\mu$ l heparin $(1000 \mathrm{U} / \mathrm{ml})$, and all were analyzed with double determinations. Plasma glucose was analyzed on a Beckmann autoanalyzer (Synchron CX-5, Beckmann, kits no. 442640 and 442785). Plasma IGF-I was measured with an RIA procedure (modified from IGF-I 100T kit, Nichols Institute, San Juan Capistrano, CA, USA), which has intra- and interassay coefficients of variation of $5.8 \%$ and $10 \cdot 1 \%$ respectively, and a detection limit of $0.3 \mathrm{ng} / \mathrm{ml}$. Plasma GH was analyzed with a double monoclonal ELISA procedure with a detection limit of $1.0 \mathrm{ng} / \mathrm{ml}$, and intra- and interassay coefficients of variation of $5 \cdot 4 \%$ and $5 \cdot 3 \%$ respectively.

ELISA for plasma rat insulin Rat insulin in plasma was analyzed with an ELISA developed at our laboratory using polyclonal antibodies from guinea pig (GP114 and GP116, SDC, Gentofte, Denmark). Immunoplates were coated with diluted anti-insulin antibody and stored at $4{ }^{\circ} \mathrm{C}$ for at least $24 \mathrm{~h}$. Samples, diluted to the appropriate concentration and calibrators prepared from rat insulin (no. 735 41118, Novo Nordisk A/S), were applied and incubated overnight at $4{ }^{\circ} \mathrm{C}$. Peroxidase-labeled detecting antibody was applied followed by TMB-enzyme substrate (3,3',5,5'-tetramethyl-benzidine peroxidase substrate, no. 50-76-00, Kierkegaard \& Perry Lab. Inc., Gaithersburg, MD, USA) prior to incubation. The reaction was stopped by adding phosphoric acid and absorption was measured at
$450 \mathrm{~nm}$ with a $620 \mathrm{~nm}$ reference (Spectra II SLT, Wallac, Turku, Finland). Cross-reaction with glucagon and IGFs -I and -II were less than 1 p.p.m. and $0.5 \%$ respectively. Recovery was between $95 \%$ and $107 \%$ and linearity was $100 \%$. Intra- and interassay coefficients of variation were less than $5 \%$ and $10 \%$ respectively. Detection limit was $0.7 \mathrm{pM}$ and the matrix effect of rat plasma was acceptable at a minimum dilution of 1:3. The correlation coefficient was $r=0.98$ between sandwich ELISA and RIA (Heding 1972).

\section{Data analysis}

The computer program SAS (SAS Institute, Cary, NC, USA) was used for analysis of the data. A two-way ANOVA was performed with the general linear models (GLM) procedure to test for significant effects across all groups. This was considered significant if the $P$ value was less than $0 \cdot 05$. If significant effects were found in the ANOVA the main effects of GH and MP were analyzed, and considered significant when $P<0 \cdot 01$. Lastly, each group mean was compared with the control group, using the Estimate option of the GLM procedure, and a $P$ value less than $0 \cdot 01$ was considered significant. The software program Excel (Microsoft Corp., Redmond, WA, USA) was used for calculation of the area under the curve (AUC). Data in the text and tables are presented as means \pm s.E.M.

\section{Results}

The results are presented in Tables 1 and 2 .

\section{Growth}

Both GH and MP had significant main effects on weight gain in both experiments. GH increased weight gain $(P<0 \cdot 001)$ while MP decreased weight gain $(P<0 \cdot 003)$. In 
Table 2 Data from study 2: weight gain, plasma IGF-I, plasma glucose levels and $\left[{ }^{3} \mathrm{H}\right]-2,6$-deoxyglucose uptake in muscle and fat 25 min after an i.v. insulin challenge $(0.5 \mathrm{U} / \mathrm{kg})$. Rats were treated for 7 days with saline (Control), rat growth hormone $2 \cdot 7 \mathrm{mg} / \mathrm{kg}(\mathrm{GH})$, methylprednisolone $5.0 \mathrm{mg} / \mathrm{kg}$ (MP) or GH and MP in the same doses as in the groups treated with only one hormone. Values are presented as means \pm S.E.M.

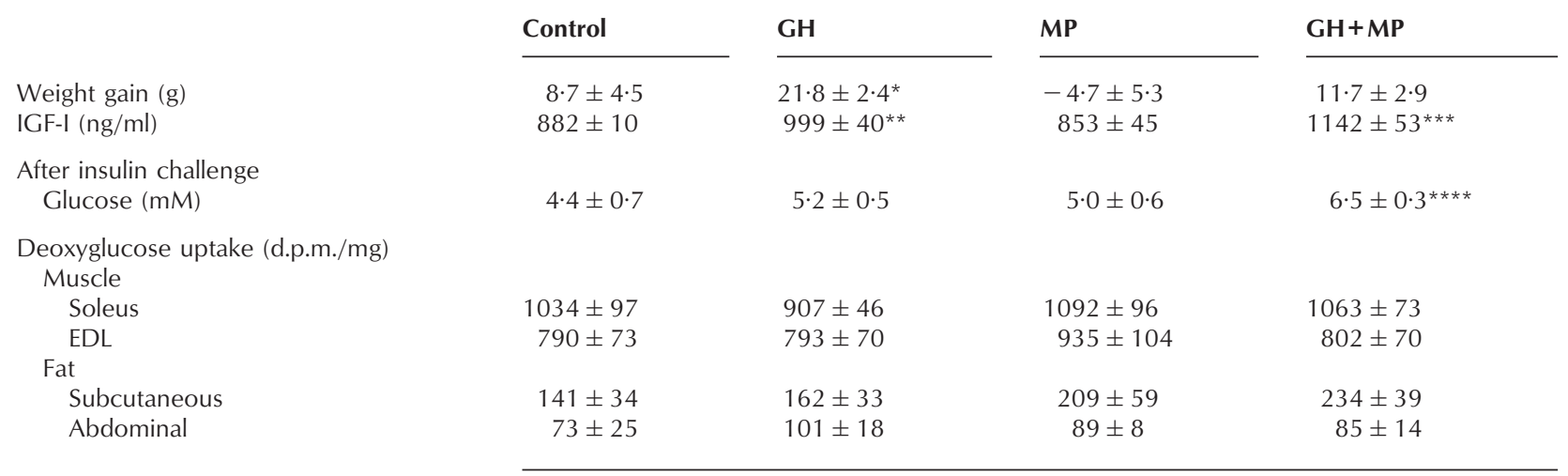

Soleus, the soleus muscle; EDL, the long extensor muscle of the digits; subcutaneous fat, subcutaneous inguinal fat; abdominal fat, intra-abdominal fat. ${ }^{*} P<0 \cdot 003,{ }^{* *} P<0 \cdot 001,{ }^{* * *} P<0 \cdot 005,{ }^{* * * *} P<0 \cdot 007$ compared with controls.

study $1 \mathrm{GH}$ treatment increased the mean body weight by $18 \cdot 7 \pm 2 \cdot 2 \mathrm{~g}(P<0 \cdot 0002)$, whereas MP inhibited weight gain: $0 \cdot 0 \pm 1 \cdot 0 \mathrm{~g}(P<0 \cdot 004)$. Treatment with both hormones resulted in a weight gain of $10 \cdot 8 \pm 1 \cdot 8 \mathrm{~g}(P<0 \cdot 2)$ which is comparable to the control value of $7 \cdot 6 \pm 1 \cdot 7 \mathrm{~g}$. Growth results from study 2 are shown in Table 2 .

\section{Growth hormone and IGF-I}

GH treatment increased GH levels approximately 40-fold, from a mean of $7 \cdot 3 \pm 2 \cdot 3 \mathrm{ng} / \mathrm{ml}$ in the controls and MP-treated animals to $302 \pm 34 \mathrm{ng} / \mathrm{ml}$ in the two groups receiving $\mathrm{GH}$. MP did not affect $\mathrm{GH}$ levels significantly $(P<0 \cdot 7)$. When comparing the two studies the IGF-I levels were slightly lower in the study where animals were chronically catheterized (study 1). Here control values were $754 \pm 34 \mathrm{ng} / \mathrm{ml}$ and after $\mathrm{GH}$ alone or in combination with MP the values were $790 \pm 60 \mathrm{ng} / \mathrm{ml}$ and $799 \pm 32 \mathrm{ng} / \mathrm{ml}$ respectively. The IGF-I level was $666 \pm 60 \mathrm{ng} / \mathrm{ml}$ after MP treatment. The IGF-I levels in study 2 were significantly elevated in the groups receiving GH $(P<0 \cdot 002)$ and were not affected by MP $(P<0 \cdot 3)$. Group means and statistics from study 2 are listed in Table 2 .

\section{Glucose tolerance test (study 1)}

The basal and peak levels of plasma glucose and insulin, as well as the glucose and insulin AUCs from the glucose tolerance test are shown in Table 1. There were no significant effects of any treatment on basal $(P<0 \cdot 4)$ and peak $(P<0 \cdot 3)$ glucose levels. Glucose AUC was increased by MP treatment $(P<0 \cdot 008)$, while GH did not affect this variable $(P<0 \cdot 9)$. However, no significant disturbances of glucose AUC were detected when comparing the individual groups with the control group (Table 1).
Basal insulin was significantly elevated by GH treatment $(P<0 \cdot 002)$, but was not changed significantly by MP injections $(P<0 \cdot 3)$. The effect of $\mathrm{GH}$ on the individual treatment groups can be seen in Table 1. Peak insulin levels were significantly decreased by $\mathrm{MP}(P<0 \cdot 009)$, whereas $\mathrm{GH}$ treatment did not change this variable $(P<0 \cdot 2)$. However, when comparing the MP-treated groups individually with the controls no significant differences were detected (Table 1). GH elevated insulin AUC significantly $(P<0 \cdot 004)$, while this was not the case after MP treatment $(P<0 \cdot 2)$. However, when comparing each group mean with the controls only the group receiving both hormones had a significantly elevated insulin AUC $(P<0 \cdot 003)$, while the increase seen after $\mathrm{GH}$ alone only approached significance $(P<0 \cdot 02)$ (Table 1$)$.

\section{Insulin challenge (study 2)}

As in study 1, basal glucose levels were not affected significantly by the hormones $(P<1 \cdot 0$, data not shown). The post insulin glucose levels were increased by $\mathrm{GH}$ treatment to a degree approaching significance $(P<0 \cdot 02)$, whereas MP did not seem to affect this variable $(P<0 \cdot 08)$. Only in the group receiving both hormones did treatment significantly increase post insulin glucose levels when compared with the control group $(P<0 \cdot 007)$ (Table 2$)$.

\section{Peripheral glucose uptake}

The ANOVA did not detect any significant treatment effects on the uptake of $\left[{ }^{3} \mathrm{H}\right]$ deoxyglucose in fat or muscle tissue. The tracer levels in each tissue are shown in Table 2 .

No significant interaction between $\mathrm{GH}$ and MP was detected in any instance. 


\section{Discussion}

This study was undertaken to examine some effects of $\mathrm{GH}$ on growth and carbohydrate handling in intact growing rats treated with the glucocorticoid, methylprednisolone.

\section{Growth}

It is well established that glucocorticoids have a catabolic effect (Horber \& Haymond 1990, Horber et al. 1991, Malmlöf et al. 1994b), which in some situations leads to wasting of nitrogen and growth retardation. With the dose regimen of MP used in the present study a majority of animals responded with an arrest of body weight gain or even a decrease. If GH was given in conjunction with MP these negative effects were prevented and animals grew at more or less the same rate as the control animals. This finding supports previous results (Kovacs et al. 1991), although some authors have reported that $\mathrm{GH}$ was not able to inhibit the catabolic effects of glucocorticoids (Ortoft et al. 1992, 1993, Malmlöf et al. 1997).

Probably, the ability of $\mathrm{GH}$ to counteract the effect of glucocorticoids on growth may depend on the levels of circulating IGF-I (Ortoft et al. 1993). In both of the experiments performed in this study $\mathrm{GH}$ appeared to normalize or elevate circulating levels of IGF-I in MPtreated animals. This was particularly noticeable in the second experiment. The glucocorticoid used in this study has a relatively short half life which might have increased the potential of $\mathrm{GH}$ to exert its anabolic effects by increasing IGF-I production.

\section{Carbohydrate metabolism}

The effects of glucocorticoids on glucose metabolism have been reported to be variable (Stojanovska et al. 1990, Haber \& Weinstein 1992, Ortoft et al. 1992, 1993, Venkatesan et al. 1996). This was probably to do with differences in the type of glucocorticoid used as well as dose and mode of administration. In this study animals treated with MP were able to maintain normal basal glucose levels. Even their ability to cope with an i.v. glucose challenge was not dramatically changed although a statistically significant main effect of MP to decrease glucose tolerance could be discerned from the data.

GH given alone or in combination with MP appeared to have no specific effects on basal glucose levels or the ability to cope with a glucose challenge. However, basal insulin levels were significantly increased in both groups receiving $\mathrm{GH}$, which is in agreement with previous studies of GH administration in rats (Hettiarachchi et al. 1996, Thirone et al. 1997). In the group receiving $\mathrm{GH}$ together with MP basal insulin levels were approximately doubled. Since basal glucose was not decreased, but rather elevated, this indicates that a certain degree of insulin resistance was present. This impression is further supported by the fact that animals in this group exhibited a significant increase in insulin AUC after an i.v. glucose challenge. Similar findings have been reported in humans (Horber et al. 1991). We are not aware of previous reports regarding glucose and insulin dynamics in rats treated with $\mathrm{GH}$ and glucocorticoid. Further confirmation of the fact that the combined treatment with GH and MP reduces insulin sensitivity was obtained when an acute insulin challenge was carried out.

Now, the interesting question arises as to which tissues are involved in the relative insulin resistance seen after combined treatment with GH and MP. One possible explanation would be a decrease in insulin-stimulated glucose transport in peripheral tissues such as fat and muscle. To our knowledge no studies dealing with this specific issue have been reported. Therefore, animals were challenged with an acute insulin injection in combination with radiolabeled glucose. The relative $\left[{ }^{3} \mathrm{H}\right]$ deoxyglucose uptake values of these individual tissues were in the same order of magnitude as described in earlier reports (Hom et al. 1984). Animals treated with GH and MP showed no difference in $\left[{ }^{3} \mathrm{H}\right]$ deoxyglucose uptake in fat or muscle but the potential of insulin to depress circulating glucose levels was significantly decreased. Although some support for these results could be found in the literature (Marfaing et al. 1991) they are surprising because there is a large body of evidence published which suggests that the elevated circulating glucose and insulin levels following treatment with GH or glucocorticoids is a consequence of peripheral insulin resistance (Pagano et al. 1983, Jorgensen et al. 1994, Fowelin et al. 1995, Hettiarachchi et al. 1996, Venkatesan et al. 1996). The reason for these conflicting results is at present not clear but the dose of insulin used might be of importance. In this study and in studies reporting similar results (Marfaing et al. 1991) a relatively high dose of insulin has been employed.

It might be asked what influence the dose of insulin has when testing the effect of GH and MP on insulinstimulated peripheral glucose uptake. One explanation for this could be that the two hormones downregulate the insulin receptors. This would shift the dose-response curve to the right, but not alter the maximal effect of insulin, as not all receptors are needed to attain the maximum response (DeFronzo 1982). Such a reasoning could perhaps explain why neither GH (Dimitriadis et al. 1994, Cartee \& Bohn 1995, Napoli et al. 1996) nor glucocorticoid (Dimitriadis et al. 1997) reduce in vitro glucose transport activity in muscle during maximal insulin stimulation. However, to elucidate this issue further in vivo dose-response curves of insulin-stimulated glucose uptake in rats treated with $\mathrm{GH}$ and/or glucocorticoid are required. Until this type of data are presented we have to conclude that the combined administration of GH and MP does not generally decrease peripheral insulin-stimulated glucose disposal. Such a conclusion is further supported by the fact that neither GH (Cartee \& Bohn 1995, Napoli 
et al. 1996) nor dexamethasone (Haber \& Weinstein 1992, Venkatesan et al. 1996, Dimitriadis et al. 1997) change the abundance of the glucose transporter molecule GLUT-4 in muscle cell membranes.

If the combination of $\mathrm{GH}$ and glucocorticoids does not decrease insulin-stimulated glucose transport peripherally then how could the decrease in insulin sensitivity be explained? One explanation could be that the hormones cause hepatic insulin resistance and that the liver consequently is principally involved in disturbing normal insulin function. This possibility is supported by the results from experiments concerning hepatic function after $\mathrm{GH}$ or glucocorticoid therapy in several species (Rizza et al. 1982, Pagano et al. 1983, Horber et al. 1991, Goldstein et al. 1993, Okuda et al. 1994, Hettiarachchi et al. 1996).

\section{Conclusions}

The growth retarding effect of glucocorticoid treatment can be overcome by $\mathrm{GH}$ administration. However, this effect is probably dependent on periods when the glucocorticoid level is relatively low and the GH level is high. In this setting GH elevated insulin levels, but development of outright insulin resistance required treatment with both hormones. Combination of the two hormones did not decrease peripheral glucose uptake in a situation with impaired glucose handling. This suggests that hepatic insulin resistance is important in this condition, probably with increased hepatic glucose mobilisation as a consequence.

\section{References}

Armstrong RB \& Phelps RO 1984 Muscle fiber type composition of the rat hindlimb. American Journal of Anatomy 171 259-272.

Cartee GD \& Bohn EE 1995 Growth hormone reduces glucose transport but not GLUT-1 or GLUT-4 in adult and old rats. American Journal of Physiology 268 E902-E909.

Dallman MF, Strack AM, Akana SF, Bradbury MJ, Hanson ES, Scribner KA \& Smith M 1993 Feast and famine: critical role of glucocorticoids with insulin in daily energy flow. Frontiers in Neuroendocrinology 14 303-347.

Davidson MB 1987 Effect of growth hormone on carbohydrate and lipid metabolism. Endocrine Reviews 8 115-131.

DeFronzo RA 1982 Insulin secretion, insulin resistance, and obesity. International Journal of Obesity 6 (Suppl 1) 73-82.

Dimitriadis G, Parry-Billings M, Leighton B, Piva T, Dunger D, Calder P, Bond J \& Newsholme E 1994 Studies on the effects of growth hormone administration in vivo on the rates of glucose transport and utilization in rat skeletal muscle. European Journal of Clinical Investigation 24 161-165.

Dimitriadis G, Leighton B, Parry-Billings M, Sasson S, Young M, Krause U, Bevan S, Piva T, Wegener G \& Newsholme EA 1997 Effects of glucocorticoid excess on the sensitivity of glucose transport and metabolism to insulin in rat skeletal muscle. Biochemical Journal 321 707-712.

Fowelin J, Attvall S, Von Schenck H, Smith U \& Lager I 1995 Characterization of the insulin-antagonistic effect of growth hormone in insulin-dependent diabetes mellitus. Diabetic Medicine 12 990-996.
Fryberg DA, Gelfand RA \& Barret EJ 1991 Growth hormone acutely stimulates forearm muscle protein synthesis in normal humans. American Journal of Physiology 260 E499-E504.

Fryberg DA, Louard RJ, Gerow KE, Gelfand RA \& Barret EJ 1992 Growth hormone stimulates skeletal muscle protein synthesis and antagonizes insulin's antiproteolytic action in humans. Diabetes $\mathbf{4 1}$ 424-429.

Goldstein RE, Wasserman DH, McGuinness OP, Lacy DB, Cherrington AD \& Abumrad NN 1993 Effects of chronic elevation in plasma cortisol on hepatic carbohydrate metabolism. American Journal of Physiology 264 E119-E127.

Haber RS \& Weinstein SP 1992 Role of glucose transporters in glucocorticoid-induced insulin resistance. GLUT-4 isoform in rat skeletal muscle is not decreased by dexamethasone. Diabetes $\mathbf{4 1}$ $728-735$.

Haymond MW \& Mauras N 1996 The rationale for the use of recombinant human growth hormone and insulin-like growth factor-I for catabolic conditions in humans. Hormone Research $\mathbf{4 6}$ 202-207.

Heding LG 1972 Determination of total serum insulin (IRI) in insulin-treated diabetic patients. Diabetologia 8 260-266.

Hettiarachchi M, Watkinson A, Jenkins AB, Theos V, Ho KK \& Kraegen EW 1996 Growth hormone-induced insulin resistance and its relationship to lipid availability in the rat. Diabetes 45 415-421.

Hom FG, Goodner CJ \& Berrie MA 1984 A $\left[{ }^{3} \mathrm{H}\right] 2$-deoxyglucose method for comparing rates of glucose metabolism and insulin responses among rat tissues in vivo. Diabetes 33 141-152.

Horber F \& Haymond MW 1990 Human growth hormone prevents the catabolic side effects of prednisone in humans. Journal of Clinical Investigation $86265-272$.

Horber FF, Marsh HM \& Haymond MW 1991 Differential effects of prednisone and growth hormone on fuel metabolism and insulin antagonism in humans. Diabetes 40 141-149.

Jorgensen JO, Pedersen SB, Borglum J, Moller N, Schmitz O, Christiansen JS \& Richelsen B 1994 Fuel metabolism, energy expenditure, and thyroid function in growth hormone-treated obese women: a double-blind placebo-controlled study. Metabolism 43 872-877.

Kovacs G, Fine RN, Worgall S, Schaefer F, Hunziker EB, Skottner-Lindun A \& Mehls O 1991 Growth hormone prevents steroid-induced growth depression in health and uremia. Kidney International 40 1032-1040.

Malmlöf K, Cortova Z, Saxerholt H, Karlsson E, Arrhenius-Nyberg V \& Skottner A 1994a Effects of insulin-like growth factor-I and growth hormone on the net flux of amino acids across the hind limbs in the surgically traumatized pig. Clinical Science 88 285-292.

Malmlöf K, Cortova Z, Saxerholt H, Arrhenius-Nyberg V, Karlsson E, Larsson C, Klingström G \& Skottner A $1994 b$ IGF-I and GH: metabolic effects during experimentally induced catabolism. In The Insulin-Like Growth Factors and their Regulatory Proteins, edn 1, pp 401-408. Eds RC Baxter, PD Gluckman \& RG Rosenfeld. Amsterdam: Elsevier Science B.V.

Malmlöf K, Arrhenius-Nyberg V, Saxerholt H \& Skottner A 1997 The role of insulin-like growth factor-I, and growth hormone in counteracting dexamethasone-induced nitrogen wasting in rats. Hormone and Metabolic Research 29 20-24.

Marfaing P, Ktorza A, Berthault MF, Predine J, Picon L \& Penicaud L 1991 Effects of counterregulatory hormones on insulin-induced glucose utilization by individual tissues in rats. Diabete et Metabolisme 17 55-60.

Napoli R, Cittadini A, Chow JC, Hirshman MF, Smith RJ, Douglas PS \& Horton ES 1996 Chronic growth hormone treatment in normal rats reduces post-prandial skeletal muscle plasma membrane GLUT-1 content, but not glucose transport or GLUT-4 expression and localization. Biochemical Journal 315 959-963.

Okuda Y, Pena J, Chou J \& Field JB 1994 Effect of growth hormone on hepatic glucose and insulin metabolism after oral glucose in conscious dogs. American Journal of Physiology 267 E454-E460. 
Ortoft G, Oxlund H, Jorgensen PH \& Andreassen TT 1992 Glucocorticoid treatment or food deprivation counteract the stimulating effect of growth hormone on rat cortical bone strength. Acta Paediatrica 81 912-917.

Ortoft G, Kelly C, Brüel A, Smith A, Carter N \& Oxlund H 1993 Glucocorticoids inhibit the growth hormone-induced increase in serum IGF-I and its mRNA, body weight and muscle mass of rats. European Journal of Experimental Musculoskeletal Research 2 135-142.

Pagano G, Cavallo Perin P, Cassader M, Bruno A, Ozzello A, Masciola P, Dall'omo AM \& Imbimbo B 1983 An in vivo and in vitro study of the mechanism of prednisone-induced insulin resistance in healthy subjects. Journal of Clinical Invesigation $\mathbf{7 2}$ 1814-1820.

Rizza RA, Mandarino LJ \& Gerich JE 1982 Effects of growth hormone on insulin action in man. Mechanisms of insulin resistance, impaired suppression of glucose production, and impaired stimulation of glucose utilization. Diabetes 31 663-669.

Stojanovska L, Rosella G \& Proietto J 1990 Evolution of dexamethasone-induced insulin resistance in rats. American Journal of Physiology 258 E748-E756.

Strack A, Sebastian RJ, Schwartz MW \& Dallman MF 1995 Glucocorticoids and insulin: reciprocal signals for energy balance. American Journal of Physiology 268 R142-R149.
Thirone AC, Carvalho CR, Brenelli SL, Velloso LA \& Saad MJ 1997 Effect of chronic growth hormone treatment on insulin signal transduction in rat tissues. Molecular and Cellular Endocrinology 130 33-42.

Venkatesan N, Lim J, Bouch C, Marciano D \& Davidson MB 1996 Dexamethasone-induced impairment in skeletal muscle glucose transport is not reversed by inhibition of free fatty acid oxidation. Metabolism: Clinical and Experimental 45 92-100.

Weinstein PS, Paquin T, Pritsker A \& Haber S 1995 Glucocorticoidinduced insulin resistance: dexamethasone inhibits the activation of glucose transport in rat skeletal muscle by both insulin- and non-insulin-related stimuli. Diabetes 44 441-445.

Yarasheski KE 1994 Growth hormone effects on metabolism, body composition, muscle mass, and strength. Exercise and Sport Sciences Reviews 22 285-312.

Received 19 June 1998

Revised manuscript received 18 January 1999 Accepted 25 February 1999 